\title{
FLUORIDE CONTENT AND LABELLING OF TOOTHPASTES MARKETED IN INDONESIA
}

\author{
Atik Ramadhani', Steffi Wijaya', Ana Mardlianah', Melissa Adiatman', Febriana Setiawati' , Harun A. Gunawan², \\ Diah A. Maharani ${ }^{1}$
}

'Department of Preventive and Public Health Dentistry, Faculty of Dentistry, Universitas Indonesia, Indonesia

${ }^{2}$ Department of Oral Biology, Faculty of Dentistry, Universitas Indonesia, Indonesia

\begin{abstract}
INTRODUCTION: Information on the fluoride content in toothpastes commercialised in Indonesia is not yet available. ОвJеCTIVES: The objective of this study is to determine the fluoride content of toothpastes marketed in Indonesia and to determine if the fluoride content is in accordance with the information provided on the packaging and following the standards from evidence-based dentistry and Indonesian regulations.

MATERIAL AND METHODs: In vitro analysis of total fluoride (TF) in 10 brands of toothpaste for adults and eight for children, purchased from different stores. The toothpastes were analysed in triplicate using a fluoride ion-selective electrode. Statistical analyses were performed using a one-sample t-test or one-sample Wilcoxon signed-rank test to compare the difference between the fluoride concentration stated on the tube and the measured value.

Results: The TF concentration in toothpastes for adults and children did not match the fluoride content provided on the packaging for most samples. Eleven toothpaste brands contained fluoride $>1000 \mathrm{ppm} \mathrm{F}$, whereas the others contained fluoride $<1000$ ppm F. Only one toothpaste contained fluoride that matched the standard from evidence-based dentistry and Indonesian regulations.

Conclusions: Most toothpastes for adults marketed in Indonesia do not meet the required fluoride concentration for caries control. The results call for strengthened regulation and quality control of fluoride toothpaste in Indonesia to provide the maximum anti-caries effect.
\end{abstract}

KEY WORDS: dental caries, fluoride, toothpastes, ion-selective electrode.

J Stoma 2020; 73, 4: 193-199

DOI: https://doi.org/10.5114/jos.2020.98265

\section{INTRODUCTION}

Dental caries are considered a global oral health burden, affecting the quality of life, and they continue to be major problems, particularly among underprivileged groups in developing countries [1-3]. The prevalence of dental caries in Indonesia, which has the largest population of all countries in southeast Asia, is reported to be considerably high [4]. Although prevention of dental caries using fluoride is apparent, dental caries continue to be the most common chronic disease affecting school children and a vast majority of adults $[5,6]$. Fluoride has been used to reduce the incidence of dental caries [7,8]. Evidence has shown that the greater the concentration of fluoride, the higher the prevention of caries $[8,9]$. When present in dental plaque and saliva, fluoride delays demineralisation and promotes remineralisation of incipient enamel lesions,

JOURNAL OF STOMATOLOGY CZASOPISMO STOMATOLOGICZNE

AdDress For CORRESPONDENCE: Dr. Diah Ayu Maharani, Department of Preventive and Public Health Dentistry, Faculty of Dentistry, Universitas Indonesia, Jalan Salemba No. 4, Jakarta 10430, Indonesia, e-mail: diah.ayu64@ui.ac.id

ReCEIVED: 22.05.2020 • ACCEPTED: 19.07.2020 • Published: 30.08.2020 
and it also inhibits cariogenic bacterial metabolism that produces acid from sugars [7].

The most widely used method in all countries to prevent caries for all ages is through the use of fluoride toothpaste. The effectiveness of toothpaste is influenced by the concentration and quantity of toothpaste, the rinsing regimen, and brushing behaviour [10]. There are three forms of fluoride in toothpaste: total fluoride (TF), total soluble fluoride (TSF), and fluoride ion (FI) [11]. A minimum concentration of $1000 \mathrm{ppm}$ of TSF is needed for a toothpaste to have adequate anti-caries property [9]. An appropriate amount of fluoride concentration should be used by children of all ages to prevent dental fluorosis. Children from first tooth eruption up to six years of age, and children older than six years should use 1000 ppm and 1450 ppm fluoridated toothpaste, respectively, under their parents' supervision [12]. Over-the-counter toothpaste is currently available with concentrations ranging from 700 to $1500 \mathrm{ppm}$, and those with 2800 and 5000 ppm are available on prescription [13]. In Indonesia, guidelines say that the total fluoride (TF) concentration in toothpaste must not exceed $0.15 \%$ or $1500 \mathrm{ppm}$, and fluoride content should be accurately labelled on the tube and on the carton [14].

Despite its benefits, fluoride toothpaste is considered a risk factor for dental fluorosis. Ingesting pea-sized amounts or more of fluoride toothpaste can lead to mild fluorosis [15]. Moreover, manufacturers, perhaps driven by consumer demand, have identified several purposes of tooth brushing, such as whitening, preventing gingivitis, and freshening breath, as well as to cope with dentin hypersensitivity. To deliver these benefits, some formulations must be optimised, whereas manufacturers can be unaware of the effects of fluoride delivery [16]. Therefore, it is important to assess the fluoride concentration in toothpaste marketed in Indonesia.

\section{OBJECTIVES}

The aim of this study is to evaluate the content of TF available in toothpastes commercialised for children and adults in Indonesia considering its anti-caries potential, as well as to discuss the recommendations for fluoride toothpastes intended for adults and children based on the best available evidence and to analyse the country's guidelines regarding the quality of toothpaste.

\section{MATERIAL AND METHODS}

This is an in vitro study to determine the TF available in toothpaste samples. Ethical clearance of this study was attained. A total of 60 over-the-counter toothpastes with fluoride content printed on the packaging were identified. Ten toothpastes commercially intended for adults and eight brands for children were randomly purchased from supermarkets and drugstores in Indo- nesia. The sampling was based on toothpastes that were the most used and easiest to obtain, and with packaging that includes information on the fluoride concentration [17]. The toothpastes were coded with letters from A to $\mathrm{R}$ to allow blinded analysis, and they were analysed before their expiration dates. The fluoride analysis was conducted using an ion-selective electrode $[18,19]$.

The analyses were carried out according to a protocol modified from the manufacturer's instruction (Metrohm ISE Application Note I-1) [20]. Briefly, $0.5 \mathrm{~g}$ of each toothpaste was vigorously homogenised in $0.5 \mathrm{ml}$ of deionised water and $0.5 \mathrm{ml}$ of $2 \mathrm{M} \mathrm{HCl}$. The suspension was heated at $90^{\circ} \mathrm{C}$ for $1 \mathrm{~min}$ to hydrolase MFP ions to $\mathrm{F}$ ions and to dissolve abrasive bound InF. The resulting suspension was cooled at room temperature, quantitatively transferred into a plastic beaker, and diluted with $100 \mathrm{ml}$ of deionised water. To measure the fluoride concentration, a reaction mixture was prepared consisting of $5 \mathrm{ml}$ of sample suspension buffered with $20 \mathrm{ml}$ of total ionic strength adjuster buffer (TISAB) IV ( $1 \mathrm{M}$ acetate buffer, $\mathrm{pH} 5.5$, containing $1 \mathrm{M} \mathrm{NaCl}$ and 0.5\% CDTA [1,2-cyclohexylenedinitrilo] tetra acetic acid). Total fluoride concentrations were assessed using an F selective electrode (Metrohm type 692, Herisau, Switzerland) coupled with the Metrohm $\mathrm{KCl}$ reference electrode. The electrode was calibrated with F standards (100-1000 ppm F), and the standard addition was performed with $\beta\left(\mathrm{F}^{-}\right)=1 \mathrm{~g} / \mathrm{l}$. In between the standard additions, the electrode was conditioned in TISAB IV for $5 \min [21]$.

A clean and dry indicator and reference electrode were inserted into the reaction mixture and swirled gently. After the reading stabilised, the result was recorded and the electrodes were removed and gently wiped with a soft tissue, dried, and left in air during analysis [22]. All the analyses were conducted in triplicate from each toothpaste tube and undertaken immediately after the toothpaste tubes were opened. For each toothpaste, the place of manufacture, type of fluoride, fluoride concentration, abrasive agent, date of manufacture, and date of expiry as shown on the tube or carton were recorded. Data were calculated and analysed statistically using SPSS software (version 23.0; SPSS Inc., Chicago, IL, USA). Statistical analyses were performed using a one-sample $t$-test or one-sample Wilcoxon signed-rank test to compare the difference between the fluoride concentration stated on the tube and the measured value. A one-way analysis of variance (ANOVA) or Kruskal-Wallis was used to determine the TF concentration every week. The statistical analysis was done by assuming a level of significant at $p<0.05$.

\section{RESULTS}

Toothpastes for adults (samples A to J) and for eight children (samples $\mathrm{K}$ to $\mathrm{R}$ ) were found in Indonesian stores. Based on their declared fluoride content, the con- 


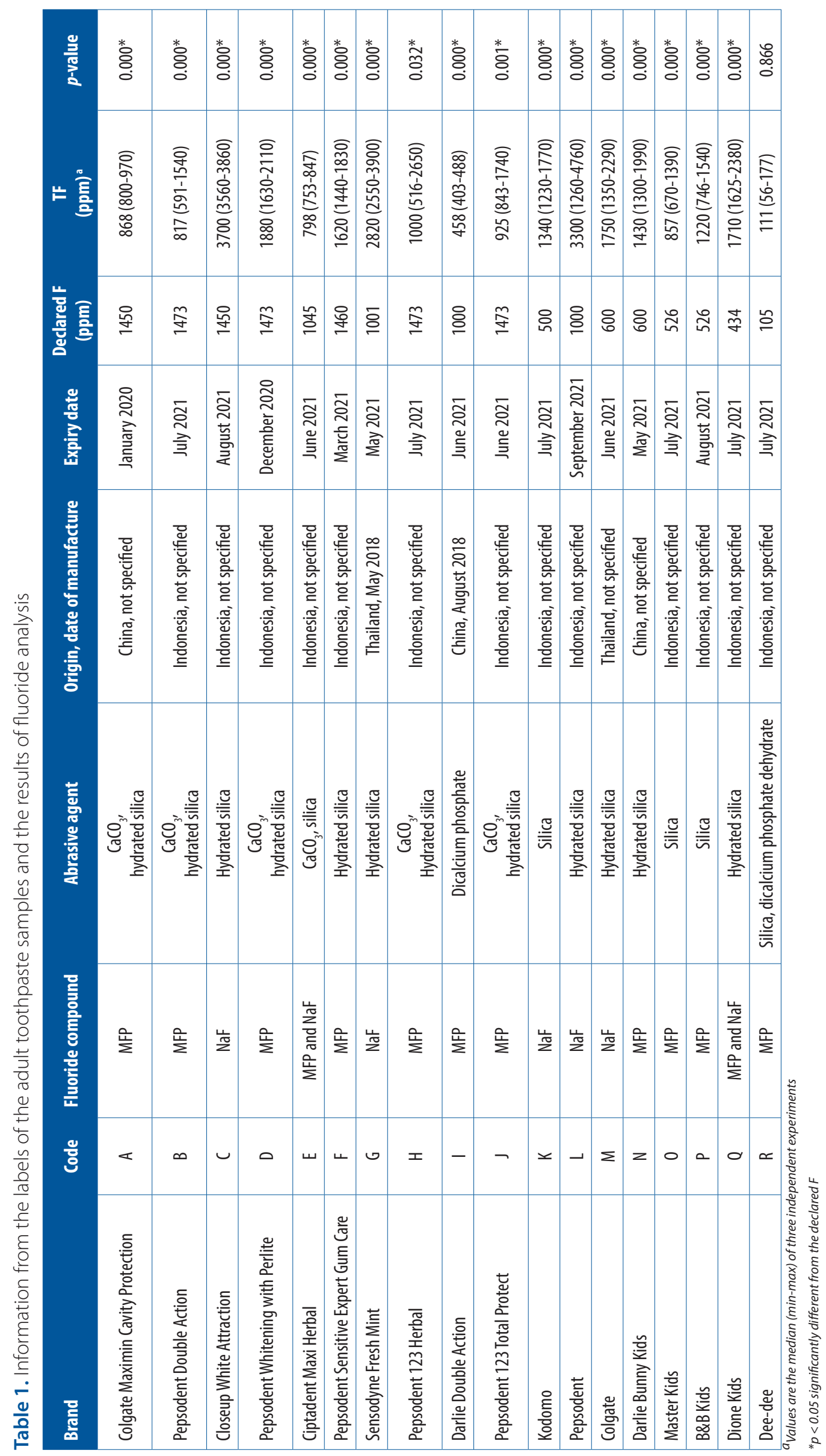


Table 2. Fluoride ion concentrations by week

\begin{tabular}{|c|c|c|c|c|c|}
\hline Brand & Code & $\begin{array}{l}\text { TF } 1^{\text {st }} \text { week }^{\mathrm{a}} \\
\text { (ppm) }\end{array}$ & $\begin{array}{c}\text { TF } 2^{\text {nd }} \text { week }^{\mathrm{a}} \\
\text { (ppm) }\end{array}$ & $\begin{array}{c}\text { TF } 3^{\text {rd }} \text { week }^{\mathrm{a}} \\
\text { (ppm) }\end{array}$ & $p$-value \\
\hline Colgate Maximin Cavity Protection & A & $940(866-970)$ & $853(841-895)$ & $859(800-881)$ & $0.005^{*}$ \\
\hline Pepsodent Double Action & B & $996(813-1540)$ & $630(591-1170)$ & $717(626-1230)$ & $0.040^{*}$ \\
\hline Closeup White Attraction & C & $3830(3650-3860)$ & $3690(3600-3830)$ & $3690(3560-3770)$ & 0.050 \\
\hline Pepsodent Whitening with Perlite & D & $2060(2020-2110)$ & $1890(1830-1920)$ & $1820(1730-1840)$ & $0.000^{*}$ \\
\hline Ciptadent Maxi Herbal & $\mathrm{E}$ & $781(753-802)$ & $814(781-833)$ & $817(761-847)$ & $0.002^{*}$ \\
\hline Pepsodent Sensitive Expert Gum Care & $\mathrm{F}$ & $1670(1590-1750)$ & $1690(1440-1830)$ & $1510(1470-1760)$ & $0.000^{*}$ \\
\hline Sensodyne Fresh Mint & G & $3500(3120-3900)$ & $2820(2740-2990)$ & $2640(2550-2780)$ & $0.000^{*}$ \\
\hline Pepsodent 123 Herbal & $\mathrm{H}$ & $1060(993-2650)$ & $706(675-1880)$ & $578(516-1860)$ & $0.030^{*}$ \\
\hline Darlie Double Action & I & $469(457-488)$ & $470(452-479)$ & $432(403-452)$ & $0.000^{*}$ \\
\hline Pepsodent 123 Total Protect & $J$ & $940(867-1740)$ & $929(861-1700)$ & $918(843-1640)$ & 0.394 \\
\hline Kodomo & K & $1725(1680-1770)$ & $1326(1300-1440)$ & $1290(1230-1360)$ & $0.000^{*}$ \\
\hline Pepsodent & L & $4240(4200-4760)$ & $3130(3070-3560)$ & $2600(2550-3330)$ & $0.000^{*}$ \\
\hline Colgate & M & $2240(2200-2290)$ & $1750(1740-1790)$ & $1390(1350-1440)$ & $0.000^{*}$ \\
\hline Darlie Bunny Kids & $\mathrm{N}$ & $1960(1860-1990)$ & $1380(1360-1410)$ & $1405(1360-1490)$ & $0.000^{*}$ \\
\hline Master Kids & 0 & $825(786-853)$ & $919(670-961)$ & $1335(1250-1390)$ & $0.032^{*}$ \\
\hline B\&B Kids & $P$ & $1250(1180-1280)$ & $864(746-890)$ & $1520(1310-1540)$ & $0.012^{*}$ \\
\hline Dione Kids & Q & $2185(2060-2380)$ & $1682(1630-1730)$ & $1675(1625-1790)$ & $0.000^{*}$ \\
\hline Dee-dee & $\mathrm{R}$ & $129(69-153)$ & $97(56-113)$ & $146(59-177)$ & 0.370 \\
\hline
\end{tabular}

a Values are the median (min-max) of three independent experiments. ${ }^{*} p<0.05$ significantly different in each week

centration of fluoride in the samples ranged from 105 to $1473 \mathrm{ppm}$. These were clearly distinguished as having a high F concentration (1000 ppm or more) (samples A, B, C, D, E, F, G, H, I, J, and L) or a low F concentration (less than $1000 \mathrm{ppm}$ ) (samples K, M, N, O, P, Q, and R). Among the fluoride toothpastes analysed, five contained natrium fluoride $(\mathrm{NaF})$ as the main active ingredient, 11 used monofluorophosphate (MFP), and two samples contained both. Regarding the abrasiveness declared by the manufacturer, NaF-based toothpastes contained sili$\mathrm{ca}$, and MFP-based contained calcium carbonate $\left(\mathrm{CaCO}_{3}\right)$ and silica. The exceptions were samples F and I, which are MFP-based toothpastes that contained silica or dicalcium phosphate as their abrasive agent, respectively (Table 1).

The concentration of TF in the samples did not coincided with the level declared on the products' labels. Only one product $(\mathrm{R})$ had a TF content consistent with the manufacturer's declaration. Samples A, B, E, H, I, and $J$ had a lower TF concentration than was stated on the label, samples C, D, F, G, K, L, M, and Q had higher concentrations than expected. Indeed, their TF concentrations were higher than the maximum allowed by the Indonesian regulation. Moreover, the TF concentrations in samples M and Q were 1750 and 1710 ppm, significantly higher than declared by the manufacturer. Sample R had the smallest TF concentration.

Furthermore, we found that the TF concentration decreased every week after the sample was opened in al- most all the samples. Statistically, only samples C, J, and $\mathrm{R}$ showed no significant difference (Table 2). All the information required by the Indonesian regulation was labelled either on the carton or tube, including the expiration date and origin. However, the date of manufacture was reported on just two samples (Table 1).

\section{DISCUSSION}

Regular use of fluoride toothpaste to reduce the prevalence and development of new dental caries has been extensively documented $[9,23,24]$. A minimum concentration of $1000 \mathrm{ppm}$ has been found to show statistically significant benefits for the prevention of dental caries [9]. Nonetheless, unclear information about the types and concentrations of fluoride has been encountered [25]. The present study is the first report regarding fluoride concentration analysis contained in toothpastes marketed in Indonesia. Because there may be discrepancies between the manufacturers' claimed amounts of fluoride and the actual TF content, fluoride concentration assessment becomes relevant. This study found that the declared TF concentrations and the levels found in the analysis were inconsistent in almost all toothpastes. Few samples had the TF level that was declared by the manufacturer $[26,27]$. The TF concentrations of all the toothpastes were lower than those declared by the manufacturers, with one in four having a TSF concentration less than 1000 ppm. 
Conversely, several studies have reported TF concentrations that matched local standards [27-29]. If strict quality control procedures are not followed, then TF concentrations are likely to vary. This difference in value is highly detrimental to consumers because the information provided is false and it violates consumer rights. Hence, there should be routine monitoring and controlling of these products.

In silica-based toothpastes, $\mathrm{NaF}$ is highly ionisable, which means that the fluoride is activated as soon as it enters the oral cavity and reduces enamel demineralisation suggesting the availability of soluble fluoride concentration [11]. Five of 18 toothpastes in this study had $\mathrm{NaF}$ as the main active ingredient and silica as the abrasive agent. The TF concentration was considerably greater in $\mathrm{NaF} / \mathrm{Si}$-based toothpastes than in others. To be effective, the added fluoride should not be chemically bound to other ingredients, especially to calcium as an abrasive. However, in most developing countries, the majority of toothpastes contain calcium carbonate because its less expensive than silica [25]. This study revealed that seven of 18 toothpaste samples had MFP as a fluoride source with calcium carbonate as the abrasive agent. In these samples, the TF concentration tended to be lower than in $\mathrm{NaF} / \mathrm{Si}$-based toothpaste. This result is consistent with a previous study developed in India, which also found that the free available soluble fluoride concentration in sodium monofluorophosphate (SMFP)/ $\mathrm{CaCO}_{3}$-based toothpastes was lower than in $\mathrm{NaF} / \mathrm{Si}$-based toothpastes: $86 \%(\mathrm{SD}=16 \%)$ and $98(\mathrm{SD}=1 \%)$, respectively [30]. To overcome this problem, manufacturers should compensate for the amount of $\mathrm{F}$ inactivated by the abrasive during product storage and ensure the availability of soluble F [28]. Unfortunately, the Indonesian regulations do not specify the amount of TF that must be maintained as soluble in the formulation of toothpastes.

This study identified significant differences in fluoride concentrations over time. All MFP-based toothpastes formulated with calcium as the abrasive agent showed lower TF concentrations over time. This may be caused by chemical changes that occur over time, converting one form of fluoride to another inside the toothpaste tube because of product instability. Therefore, MFP-based toothpastes should be formulated with calcium carbonate because the fluoride is firmly bound to the phosphate component to ensure the availability of soluble F during storage. However, that bond is unstable. MFP undergoes hydrolysis over time and releases $\mathrm{F}$ ions that react with calcium to form insoluble calcium fluoride $\left(\mathrm{CaF}_{2}\right)$ in the toothpaste, thus reducing the preventive effects [28]. Regarding NaF-based toothpastes, some studies have shown that $\mathrm{NaF}$ formulated with silica is more stable than when calcium carbonate is the abrasive agent [29]. In the present study, samples G, K, L, and M showed statistically different TF concentrations within a week. This may be related to storage conditions, because time and temperature tend to reduce the effectiveness of the fluo- ride concentration. Most manufacturers did not provide the date of manufacture. This raises concerns about the effectiveness of toothpaste if it is stored for a long period. Another concern is that high storage temperature may affect the stability of fluoride, because an increased temperature can accelerate hydrolysis [27]. It should be emphasised that the time that toothpaste stays in a store is estimated to be approximately three months. It should be at a temperature under $26.3^{\circ} \mathrm{C}$ to maintain the soluble fluoride that provides the anti-caries effect. Further analysis regarding the detailed ingredients of the toothpaste should be developed to collect more information.

The limitations of our study are related to the method of analysis, which determines only the TF, whereas a toothpaste's anti-caries effectiveness can be considered only from the amount of fluoride ion dissolved in the oral cavity (TSF) $[9,11,28]$. Nonetheless, most of the evaluated toothpastes showed similar measured TSF in NaF/Si-based toothpastes and 15-50\% less TSF than MFP-based toothpastes with calcium-containing abrasives $[11,26,28,30]$. Future studies should be performed to analyse the TSF concentration of each toothpaste to gain more information about the amount of fluoride that is left in the oral cavity when brushing teeth. However, the present study does provide results that can contribute to the current regulation and recommendation about the fluoride concentrations marketed in Indonesia. When analysing the TF concentration, only 11 of 18 toothpastes contained TF higher than $1000 \mathrm{ppm}(\mathrm{C}, \mathrm{D}, \mathrm{F}, \mathrm{G}, \mathrm{H}, \mathrm{K}, \mathrm{L}, \mathrm{M}, \mathrm{N}, \mathrm{P}$, and Q) - the minimum concentration needed to be effective against caries [9]. Only 3 out of 10 adult toothpastes (C, D, and G) contained TF higher than the 1500 ppm recommended for people at high risk for dental caries. Toothpaste $\mathrm{H}$ contained TF at exactly 1000 ppm, but considering the presence of calcium abrasive in the formulation, the soluble fluoride may be lower than 1000 ppm, which was not effective against caries. The adult toothpastes with more than 1000 ppm of fluoride that were formulated with $\mathrm{MFP} / \mathrm{CaCO}_{3}$ demonstrated that using MFP as the fluoride form is not chemically stable when paired with calcium. Differences between declared fluoride by manufactures and the obtained results of this study should be interpreted with caution. Limitations of this study might potentially occur due to discrepancy in the materials and methods applied.

The use of fluoride toothpaste with children has been subjected to several systematic reviews $[9,13,15]$. The European Academy of Paediatric Dentistry recommended that the minimum concentration of fluoride in toothpaste for children is $1000 \mathrm{ppm}$, whereas the FDI World Dental Federation advocates the use of over-the-counter toothpaste with a fluoride concentration between 1000 and 1500 ppm, with a minimum of 800 ppm F ion bioavailability [12]. Fluoride toothpastes (K, N, and P) with F concentrations of 1000-1450 ppm are recommended for children below six years of age under the supervision 
of parents. A smear of fluoride toothpaste was recommended for children from the first tooth to two years of age, while a pea-sized amount was recommended for children between two and six years of age. Toothpaste with a concentration lower than $1000 \mathrm{ppm}(\mathrm{R}$ and $\mathrm{O})$ can be considered for young children if they are regularly exposed to other sources of fluoride [12]. Toothpastes with a high concentration of fluoride (more than $1450 \mathrm{ppm}$ like samples L, M, and Q) are not recommended for children under six years of age, except by prescription. However, the labels state that they are recommended for children under the age of six years. These particular products could pose a serious risk as they contains threefold higher F content than declared.

Many countries have no specific regulation concerning the actual amount of soluble fluoride in toothpaste $[25,27,28]$. Indonesia's regulation states that the TF concentration in toothpaste should not exceed $0.15 \%$ or 1500 ppm; it does not define the minimum TSF concentration. These standards leave consumers unprotected due to the poor anti-caries efficacy of some toothpastes. The need to review the guidelines about the quality of fluoride in marketed toothpastes is crucial. Regulation should ensure a minimum of 1000 ppm TSF concentration in toothpaste formulations. Quality control, standard settings, and compliance are required.

\section{CONCLUSIONS}

The TF content in the toothpastes analysed was not consistent with the amount declared by the manufacturers, and some samples contained higher concentrations of TF than recommended by the country's regulations. It is necessary to review the regulation about the amount of soluble fluoride in toothpaste to provide the maximum anti-caries effect and maintain the quality of toothpaste production.

\section{CONFLICT OF INTEREST}

The authors declare no potential conflicts of interest with respect to the research, authorship, and/or publication of this article.

\section{References}

1. Thomson WM, Broder HL. Oral-health-related quality of life in children and adolescents. Pediatr Clin North Am 2018; 65: 1073 1084 .

2. Maharani DA, Adiatman M, Rahardjo A, Burnside G, Pine C. An assessment of the impacts of child oral health in Indonesia and associations with self-esteem, school performance and perceived employability. BMC Oral Health 2017; 17: 65. DOI: https://doi. org/10.1186/s12903-017-0358-5.

3. Rachmawati YL, Pratiwi AN, Maharani DA. Cross-cultural adaptation and psychometric properties of the Indonesia version of the scale of oral health outcomes for 5-year-old children. J Int Soc Prev Community Dent 2017; 7: S75-S81.
4. Maharani DA, Zhang S, Gao SS, Chu CH, Rahardjo A. Dental caries and the erosive tooth wear status of 12-year-old children in Jakarta, Indonesia. Int J Environ Res Public Health 2019; 16: 2994.

5. Petersen PE, Ogawa H. Prevention of dental caries through the use of fluoride - the WHO approach. Community Dent Health 2016; 33: 66-68

6. Tickle M, Ricketts DJN, Duncan A, et al. Protocol for a randomised controlled trial to evaluate the effectiveness and cost benefit of prescribing high dose fluoride toothpaste in preventing and treating dental caries in high-risk older adults (reflect trial). BMC Oral Health 2019; 19: 88.

7. O'Mullane DM, Baez RJ, Jones S, et al. Fluoride and oral health. Community Dent Health 2016; 33: 69-99.

8. Tavss EA, Mellberg JR, Joziak M, Gambogi RJ, Fisher SW. Relationship between dentifrice fluoride concentration and clinical caries reduction. Am J Dent 2003; 16: 369-374.

9. Walsh T, Worthington HV, Glenny AM, Marinho VC, Jeroncic A. Fluoride toothpastes of different concentrations for preventing dental caries. Cochrane Database Syst Rev 2019; 3: CD007868.

10. Creeth J, Zero D, Mau M, Bosma ML, Butler A. The effect of dentifrice quantity and toothbrushing behaviour on oral delivery and retention of fluoride in vivo. Int Dent J 2013; 63 Suppl 2: 14-24.

11. Chávez BA, Vergel GB, Cáceres CP, Perazzo MF, Vieira-Andrade RG, Cury JA. Fluoride content in children s dentifrices marketed in Lima, Peru. Braz Oral Res 2019; 33: e051.

12. Toumba KJ, Twetman S, Splieth C, Parnell C, van Loveren C, Lygidakis NA. Guidelines on the use of fluoride for caries prevention in children: an updated EAPD policy document. Eur Arch Paediatr Dent 2019; 20: 507-516.

13. Scottish Intercollegiate Guidelines Network (SIGN). Dental interventions to prevent caries in children. Edinburgh: SIGN; 2014.

14. Republik Indonesia. BPOM. Persyaratan teknis bahan kosmetika. Jakarta; 2015, 2044.

15. Wright JT, Hanson N, Ristic H, Whall CW, Estrich CG, Zentz RR. Fluoride toothpaste efficacy and safety in children younger than 6 years: a systematic review. J Am Dent Assoc 2014; 145: 182-189.

16. Lippert F. An introduction to toothpaste - its purpose, history and ingredients. Monogr Oral Sci 2013; 23: 1-14.

17. Martinez-Mier EA, Tenuta LMA, Carey CM, et al. European Organization for Caries Research Workshop: methodology for determination of potentially available fluoride in toothpastes. Caries Res 2019; 53: 119-136.

18. World Health Organization. Basic methods for assessment of renal fluoride excretion in community prevention programmes for oral health. Geneva: WHO; 2014.

19. Sebastian ST, Siddanna S. Total and free fluoride concentration in various brands of toothpaste marketed in India. J Clin Diagn Res 2015; 9: ZC09-12.

20. Widianti TA, Bahar A, Maharani DA, Tumen EC, Yavuz I. Effect of silver diamine fluoride application on fluoride concentration in saliva. J Phys Conf Ser 2018; 1073: 052001.

21. Sari DL, Bahar A, Gunawan HA, et al. Fluoride concentration in urine after silver diamine fluoride application on tooth enamel. J Phys Conf Ser 2017; 884: 012054.

22. Agustanti A, Maharani DA, Gunawan HA, Callea M. The measurement of fluoride ion in anchovy (Stolephorus insularis) using ion selective electrode. J Phys Conf Ser 2018; 1073: 022001.

23. Jepsen S, Blanco J, Buchalla W, et al. Prevention and control of dental caries and periodontal diseases at individual and population level: consensus report of group 3 of joint EFP/ORCA workshop on the boundaries between caries and periodontal diseases. J Clin Periodontol 2017; 44 Suppl 18: S85-S93.

24. Whelton HP, Spencer AJ, Do LG, Rugg-Gunn AJ. Fluoride revolution and dental caries: evolution of policies for global use. J Dent Res 2019; 98: 837-846.

25. van Loveren C, Moorer WR, Buijs MJ, van Palenstein Helderman WH. Total and free fluoride in toothpastes from some non-established market economy countries. Caries Res 2005; 39: 224-230. 
26. Vorster L, Naidoo S, Stauf N, Holmgren C, Benzian H. Fluoride content of toothpastes available in South Africa. Community Dent Health 2018; 35: 186-192.

27. Benzian H, Holmgren C, Buijs M, van Loveren C, van der Weijden F, van Palenstein Helderman W. Total and free available fluoride in toothpastes in Brunei, Cambodia, Laos, the Netherlands and Suriname. Int Dent J 2012; 62: 213-221.

28. Cury JA, Oliveira MJL, Martins CC, Tenuta LMA, Paiva SM. Available fluoride in toothpastes used by Brazilian children. Braz Dent J 2010; 21: 396-400.

29. Loureiro LA, Fager AF, Santos Moreira MJ, Maltz M, Hashizume LN Fluoride availability and stability in children's toothpastes in Uruguay. J Dent Child 2017; 84: 52-57.

30. Thakkar VP, Rao A, Rajesh G, Shenoy R, Pai M. Fluoride content and labelling of toothpastes marketed in India. Community Dent Health 2015; 32: 170-173. 